\title{
Perancangan Dan Penerapan Sistem Penjualan Berbasis Web Pada Restoran Tengkleng Mbah Ninik
}

\author{
Noor Aidha Amilia ${ }^{1}$, Mukhamad Nurkamid ${ }^{2}$, Tri Listyorini ${ }^{3}$ \\ ${ }^{1-3}$ Program Studi Teknik Informatika, Fakultas Teknik, Universitas Muria Kudus \\ Email: ${ }^{1}$ noor.aidhaa@ gmail.com, ${ }^{2}$ muhammad.nurkamid@umk.ac.id, ${ }^{3}$ trilistyorini@umk.ac.id
}

(Naskah masuk: 1 November 2021, diterima untuk diterbitkan: 11 Desember 2021)

\begin{abstract}
Abstrak
Penjualan adalah aktivitas dalam menjual produk ataupun jasa. Permasalahan yang ada dalam proses penjualan yaitu kurang optimalnya pemilik dalam mengelola penjualan. Banyak pemilik usaha dalam mencatat data masuk maupun keluar masih manual. Akibatnya sangat mungkin terjadi kesalahan dalam mencatat, serta kehilangan data. Maka terjadilah perbedaan data, terjadi kesalahan data, salah maupun kurang dalam menghitung. Maka dari itu dibutuhkannya sistem penjualan supaya owner usaha makanan dan minuman dapat terbantu dalam proses penjualannya, seperti Restoran Tengkleng Mbah Ninik ketika mengolah data. Maka dengan adanya sebuah aplikasi sistem penjualan maka dapat membantu pemilik usaha dalam memperbarui data setiap ada transaksi. dan setiap saat dapat mengecek proses transaksi melalui web. Dalam pembuatan aplikasi sistem penjualan, pada pengembangan aplikasi penulis menggunakan metode waterfall. Dan menggunakan metode black box, white box dan user acceptance testing pada hasil implementasi dan pengujian yang dilakukan didapatkan bahwa sistem penjualan yang dibangun dapat membantu dan meningkatkan kinerja di restoran Tengkleng Mbah Ninik Kudus.
\end{abstract}

Kata kunci: Penjualan, Web, Usaha, Makanan dan Minuman, Waterfall

\section{DESIGN AND IMPLEMENTATION OF WEB-BASED SALES SYSTEM AT TENGKLENG MBAH NINIK RESTAURANT}

\begin{abstract}
Sales is an activity in selling products or services. The problem that exists in the sales process is that the owner is less than optimal in managing sales. Many business owners in recording incoming and outgoing data are still manual. As a result, it is very possible for errors to occur in recording, as well as data loss. Then there is a difference in data, data errors occur, wrong or less in calculating. Therefore, a sales system is needed so that food and beverage business owners can be assisted in the sales process, such as Tengkleng Mbah Ninik Restaurant when processing data. So with a sales system application, it can help business owners in updating data every time there is a transaction. and at any time can check the transaction process via the web. In making the sales system application, in developing the application the author uses the waterfall method. And using the black box, white box and user acceptance testing methods on the results of the implementation and testing carried out, it was found that the sales system built can help and improve performance at Tengkleng Mbah Ninik restaurant Kudus.
\end{abstract}

Keywords: Sales, Web, Business, Food and Beverage, Waterfall

\section{PENDAHULUAN}

Dalam dunia bisnis, ketika konsumen mendapatkan kepuasaan maka bisa dikata kan sebagai suatu keberhasilan dalam memenuhi kebutuhan dan layanan penjualan. Maka dari itu banyak pemilik usaha yang meningkatkan kualitas produk dan pelayanan. Selain itu dalam dunia bisnis persaingan usaha juga semakin ketat (Permana, Silvester Dian Handy, 2015). Namun pemilik usaha masih kesulitan dalam menangani rekapitulasi data penjualan, beberapa tempat usaha dalam melakukan rekapitulasi data masih menggunakan manual. Akibatnya (Pamungkas and Yuliansyah, 2017) Pada rekapitulasi data pemilik usaha kesulitan ketika harus menginputkan data penjualan dan pembelian satu persatu perharinya. Data tersebut akan disimpan dalam file excel, setiap transaksi akan disimpan pada satu sheet dan satu file perharinya yang menjadi sangat banyak file yang ada. Maka dibutuhkan suatu sistem penjualan yang dapat mendata setiap ada 
transaksi, dan dapat secara lengkap dan detail. Selain itu dapat dengan mudah menjumlahkan hasil penjualan pada saat itu juga atau kapan saja sehingga dapat mempermudah pemilik usaha.

Restoran tengkleng mbah ninik kudus merupakan salah satu restoran yang menyediakan berbagai macam menu tengkleng dan nasi goreng. Permasalahan yang ada adalah seringkali pemilik usaha tidak tau pasti tentang berapa persisnya jumlah seluruh omset penjualan yang didapatkannya, dan hanya bisa memperkirakan saja. Dan membutuhkan waktu sampai berhari-hari jika memerintahkan karyawan untuk merekap omset. Dan membutuhkan waktu yang panjang dalam melakukan proses pengecekan jumlah pasti dari stok, jika tanpa informasi yang akurat dan bisa cepat diakses. Sistem penjualan dapat membantu pemilik usaha melalui teknologi agar mendapatkan informasi yang real time. Maka dari itu sistem penjualan sangat diperlukan (Ferdika and Kuswara, 2017). Dengan adanya sistem penjualan dapat mempermudah pemilik usaha dalam mengamati kondisi penjualan, apakah naik ataupun turun. selain itu dapat mengetahui dengan cepat menu apa saja yang paling banyak diminati atau yang paling banyak terjual dalam bulan atau tahun tertentu.

Sistem penjualan dapat melakukan penginputan menu, stok menu, mengatur harga, melihat data transaksi dan grafik penjualan. Penelitian terkait tentang sistem penjualan dilakukan oleh Sugihartono, dkk dalam (Sugihartono et al., 2015) yang memaparkan tentang pembuatan aplikasi point of sales toko cabang perusahaan torani menggunakan framework codeigniter. Pada paper tersebut membahas tentang pemesanan barang yang dapat dilakukan dengan mudah tanpa melakukan pemesanan melewati telepon, serta pendataan dan transaksi menjadi lebih efisien dengan adanya aplikasi tersebut. Dalam (Sani, Pradana and Rusdianto, 2018) Dijelaskan bahwa pembuatan aplikasi point of sales yang dapat memudahkan pemilik dalam melihat informasi mengenai tiap outlet yang dapat dilihat secara real time tanpa melakukan pembukuan yang membutuhkan banyak waktu. Penelitian lain dalam (Sari, Prasetyo and Santosa, 2016) Menjelaskan tentang aplikasi point of sales berbasis web yang dapat mengelola penjualan agar memudahkan pemilik usaha. Serta dalam melihat laporan penjualan obat menjadi lebih mudah. Penelitian terkait lainnya yaitu dalam (Herman, Rostianingsih and Setiawan, 2016) yang membahas tentang aplikasi point of sales yang memiliki fitur-fitur diantaranya yaitu dapat menampilkan pesanan, memudahkan dalam melakukan reservasi, memudahkan ketika ingin menambahkan promo, selain itu juga dapat melakukan edit pesanan di dapur dengan cara mengganti statusnya, menampilkan laporan penjualan dan memudahkan mengatur stok.

\section{METODE PENELITIAN}

\subsection{Objek Penelitian}

Berdasarkan pada pendahuluan diatas, penulis memilih obyek penelitian di Restoran Tengkleng Mbah Ninik. Objek penelitian berupa informasi yang dibutuhkan penulis dalam pembuatan aplikasi.

\subsection{Jenis dan Sumber Data}

Untuk menghasilkan data yang akurat, menentukan data dan sumber data sangat penting. Berikut jenis data yang digunakan pada penelitian ini yaitu:

1. Data Primer

Data primer merupakan data yang diambil secara langsung dari objek penelitian yang dilakukan oleh peneliti. Data primer yang diambil penulis berikut yaitu Daftar menu, daftar harga dan data penjualan.

2. Data Sekunder

Data sekunder adalah data yang secara tidak langsung didapat dari objek penelitian, data yang didapat berasal dari buku-buku, internet dan sebagainya. Data sekunder digunakan untuk melengkapi data primer. Sumber literatur yang digunakan adalah jurnal, makalah dan buku yang membahas tentang sistem penjualan.

\subsection{Metode Pengumpulan Data}

Metode pengumpulan data yang digunakan antara lain:

1. Studi Pustaka

Studi kepustakaan adalah metode pengumpulan data yang dilakukan dengan cara membaca, mencari dan mengumpulkan dokumen-dokumen sebagai referensi seperti artikel, buku dan literatur tugas akhir pada topik yang dipilih dalam kaitannya dengan topik penelitian. Penulis menggunakan literature review untuk mendapatkan informasi tambahan mengenai sistem penjualan, dll.

2. Wawancara

Teknik pengumpulan data mengenai sumber informasi secara langsung sehingga penulis bisa mendapatkan banyak informasi dari sumbernya.

3. Observasi

Pengumpulan data melalui pencatatan dan observasi tentang peristiwa atau gejala yang diperiksa pada subjek pemeriksaan. Tidak ada interaksi langsung antara objek yang diamati dengan pengamat atau pengumpul data. Manfaat observasi antara lain:

a. Data yang diterima adalah yang terbaru karena merupakan hasil dari keadaan yang terjadi pada saat itu.

b. Data lebih objektif dan jujur, karena objek penelitian atau responden tidak dapat mempengaruhi pengumpul data. 


\subsection{Perencanaan Sesuai Metode Pengembangan} Sistem

Dalam pembuatan sistem ini penulis menggunakan metode waterfall sesuai dengan referensi (Sommerville, 2011) adalah metode yang menggambarkan proses software development dalam aliran sequential. Model waterfall yaitu suatu metodologi pengembangan perangkat lunak yang mengusulkan pendekatan sistematis dan berurutan untuk perangkat lunak yang dimulai pada tingkat kemajuan sistem melalui analisis, desain, kode, pengujian, dan pemeliharaan. Jika telah memasuki tahap selanjutnya dalam project ini, maka tidak dapat kembali. Rencana yang dibuat pada setiap fase dijelaskan di bawah ini berdasarkan metode pengembangan sistem yang dipilih, yaitu:

\section{Requirement analysis and Definition}

Mengumpulkan kebutuhan secara lengkap kemudian dianalisis dan didefinisikan persyaratan yang harus dipenuhi oleh program yang akan dibuat. Tahapan ini merupakan proses dimana penulis menentukkan klasifikasi data yang akan membantu dan mendukung dalam perancangan basis data untuk mempermudah dan memperjelas dalam pengaksesan program yang akan dibuat.

Penulis mengumpulkan data mulai dari menu, harga, dan data penjualan kemudian menganalisa data tersebut agar sesuai dengan yang dibutuhkan.

\section{System and Software Design}

Desain sistem merupakan tahap perakitan proses yang optimal, data, alur proses dan hubungan antar data untuk menjalankan proses bisnis dan memenuhi kebutuhan sesuai hasil analisis kebutuhan.

Pada fase ini penulis menentukan dan melakukan perancangan sistem dan alur proses dari sistem yang akan dirancang.

\section{Implementation and Unit Testing}

Fase ini merupakan fase dimana desain yang dibuat ditransformasikan menjadi sebuah sistem yang dapat dijalankan sesuai kebutuhan. Tahap ini adalah pengkodean desain dalam bahasa pemrograman.

Pada tahap ini, penulis memulai pengkodean menggunakan bahasa pemrograman yang diberikan untuk membuat desain sistem dan alur proses yang telah dirancang sebelumnya.

\section{Integration and System Testing}

Diperlukan proses pengujian agar sistem aplikasi yang dibuat dapat memberikan hasil yang optimal dan berfungsi dengan baik. Pendekatan yang digunakan yaitu blackbox, whitebox, dan user acceptance.
Penulis menguji aplikasi yang dibuat untuk melihat apakah sistem berjalan sesuai yang diinginkan.

\section{Operation and Maintenance}

Ini merupakan tahap perawatan sistem yang telah dikembangkan seperti perawatan perangkat lunak, perawatan media lain dan perangkat keras yang berhubungan dengan komputer.

Selama fase ini, kinerja perangkat lunak juga harus dijaga agar berfungsi dengan baik. Pada tahap akhir ini, penulis melakukan perawatan hardware dan software agar performa yang dibuat tetap stabil.

\section{HASIL DAN PEMBAHASAN}

Hasil dan pembahasan menjelaskan mengenai analisis dan perancangan sistem yang akan dibuat dan melakukan implementasi pada sistem penjualan.

\subsection{Analisa dan Perancangan Sistem}

Perancangan sistem dibuat agar memudahkan dalam memahami alur kerja pada pembutaan sistem penjualan yang menggunakan metode perancangan terstruktur. Dengan menggunakan pendekatan terstruktur hasil dari sistem tersebut lebih mudah dipelihara sehingga dapat memuaskan pemakainya, serta sesuai dengan anggaran biaya pengembangannya dan menghasilkan kualitas yang lebih baik(Vera, 2018). Pada metode terstruktur, ada yang berbentuk grafik yaitu salah satunya Data Flow Diagram (DFD), kemudian berupa bagan yaitu flowchart(Ayu Y. Primashanti, 2015).

Pada gambar 1 merupakan flowchart yang menggambarkan sistem penjualan. Flowchart merupakan urutan proses yang digambarkan dengan detail, serta hubungan antar proses dalam suatu program yang digambarkan dengan suatu bagan. Selain itu dapat menjelaskan secara rinci langkah-langkah proses dari suatu program (Yakub, 2012). Pada flowchart tersebut menjelaskan tentang alur program pada saat customer melakukan pemesanan. Mulai dari ketika customer memilih apakah ingin makan ditempat atau dibawa pulang. Kemudian ketika memilih makan ditempat harus menginputkan nama terlebih dahulu, setelah itu memilih nomor meja terlebih dahulu. Sedangkan jika memilih untuk take away, ditulis namanya. Selanjutnya, pilih menu makanan dan minuman yang ingin dipesan. Setelah itu pilih checkout. Setelah itu dilanjutkan dengan melakukan pembayaran di kasir. 


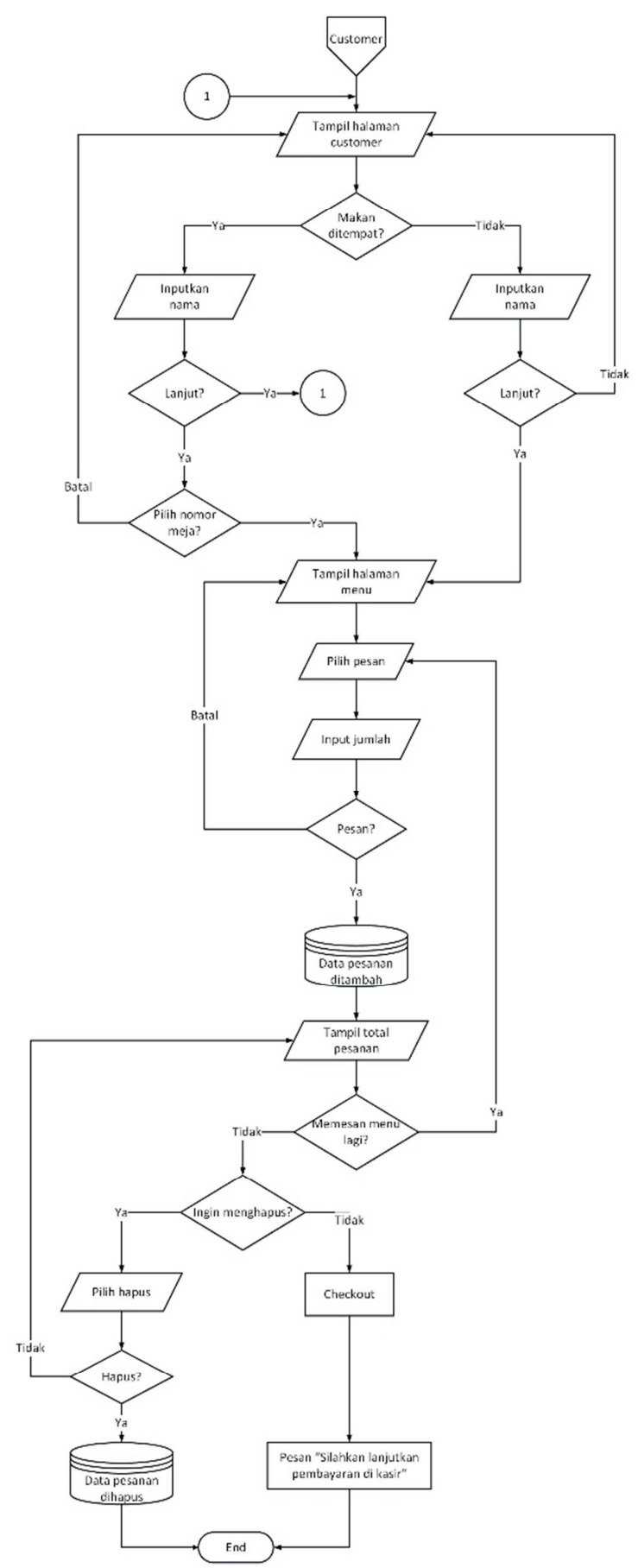

Gambar 1. Flowchart halaman pelanggan

Gambar 2 menjelaskan alur program di menu transaksi. Dijelaskan saat kasir melakukan proses transaksi mulai dari pemilihan nomor meja atau nama pelanggan yang ingin melakukan proses pembayaran. Jika pelanggan telah melakukan pemesanan sebelumnya, nomor meja secara otomatis diaktifkan dan nama pelanggan muncul saat mereka tidak makan di tempat tersebut. Kemudian melalui proses perhitungan dan diakhiri dengan mencetak struk pembayaran.

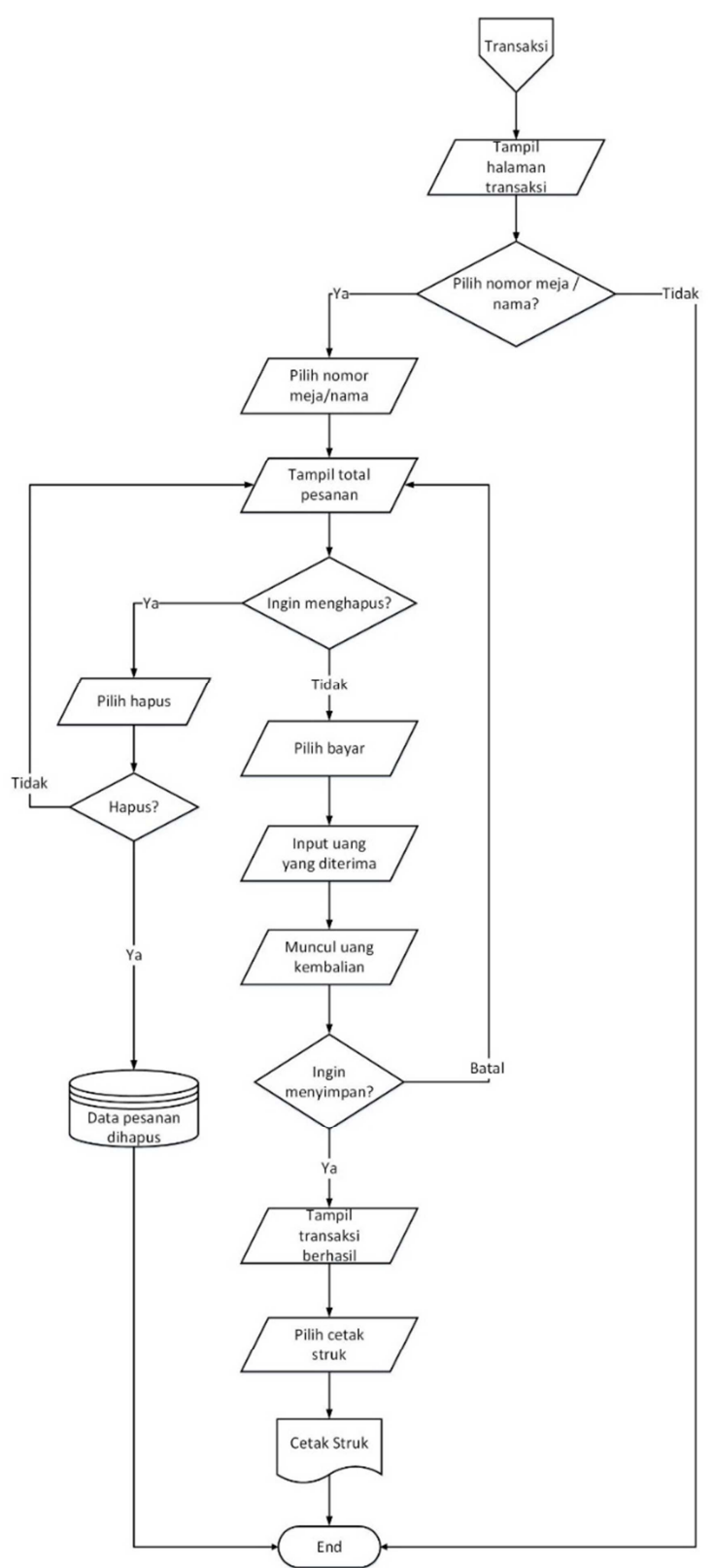

Gambar 2. Flowchart halaman transaksi

Gambar 3 menunjukkan Data Flow Diagram (DFD) dari sistem penjualan yang dibangun. DFD menunjukkan gambaran proses input dan output suatu sistem atau perangkat lunak, yaitu objek data mengalir ke dalam perangkat lunak, kemudian ditransformasikan oleh elemen pemroses, dan objek data yang dihasilkan akan mengalir keluar sistem/perangkat lunak. DFD pada dasarnya digambarkan dalam bentuk hierarki, yang pertama sering disebut sebagai DFD level 0, menggambarkan sistem secara keseluruhan, sedangkan DFD selanjutnya merupakan perbaikan dari DFD(Soufitri, 2017) sebelumnya. DFD level 0 menunjukkan sistem operasi umum dan pengguna yang dapat mengakses sistem. Sistem penjualan ditujukan hanya untuk administrator, kasir, pelanggan dan pemilik yang dapat menggunakan sistem. Admin dapat mengelola data pegawai, akun, stok, menu, outlet, 
meja, grafik penjualan dan total terjual. Kasir dapat melakukan pengelolaan data meja, transaksi, dan cetak struk, customer dapat melakukan pemesanan, sedangkan pemilik dapat melakukan lihat penjualan.

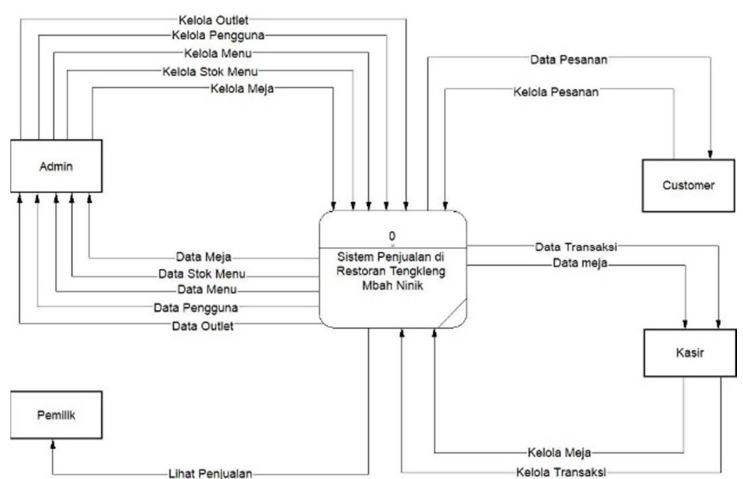

Gambar 3. Data Flow Diagram (DFD)

Gambar 4 menunjukkan diagram dekomposisi yang merupakan pemecahan sistem dari DFD level 0 , dfd level 1, dfd level 2 proses 1, dfd level 2 proses 2 dan seterusnya.

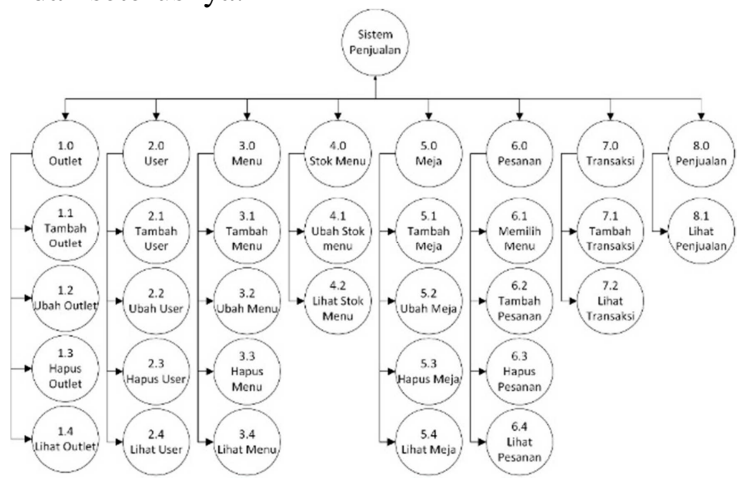

Gambar 4. Diagram Dekomposisi

\subsection{Implementasi dan Pengujian}

Bagian ini memaparkan hasil implementasi sistem penjualan yang dibangun. Berikut adalah tampilan antarmuka sistem penjualan Restoran Tengkleng Mbah Ninik.

1. Tampilan halaman pelanggan

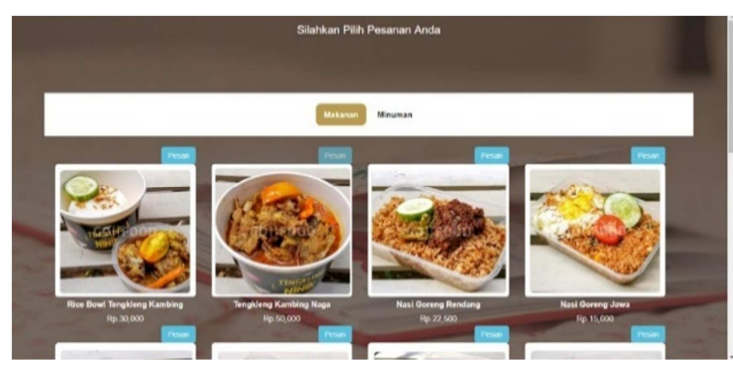

Gambar 5. Implementasi Halaman pelanggan

Halaman pelanggan berfungsi untuk melihat menu makanan dan minuman yang bisa dipesan pelanggan. Cukup pilih tombol pesan jika pelanggan ingin memilih menu yang diinginkan. Terdapat gambar menu untuk memudahkan pelanggan saat ingin memesan menu. Jadi tidak hanya nama menunya saja. Dibawah gambar terdapat nama menu dan harga dari menu tersebut. Pada atas gambar terdapat tombol pesan untuk memesan makanan tersebut.

\section{Tampilan halaman transaksi}

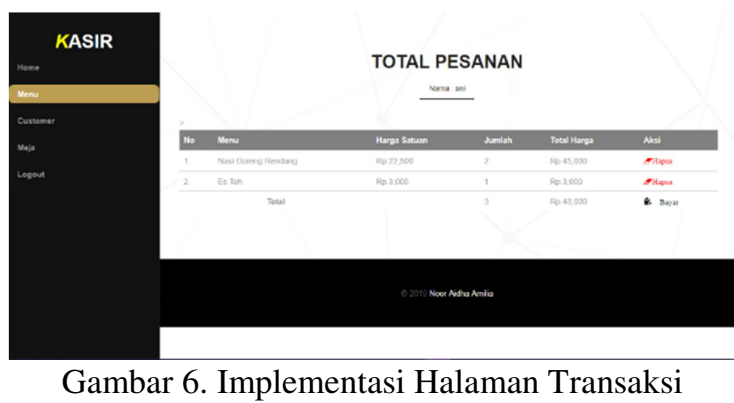

Gambar 6 menunjukkan halaman transaksi yang berfungsi ketika data pemesanan yang sudah dilakukan oleh customer juga terdapat total keseluruhannya pada paling bawah. digunakan oleh kasir dalam memproses transaksi saat melakukan pemesanan.

\section{Tampilan halaman total terjual}
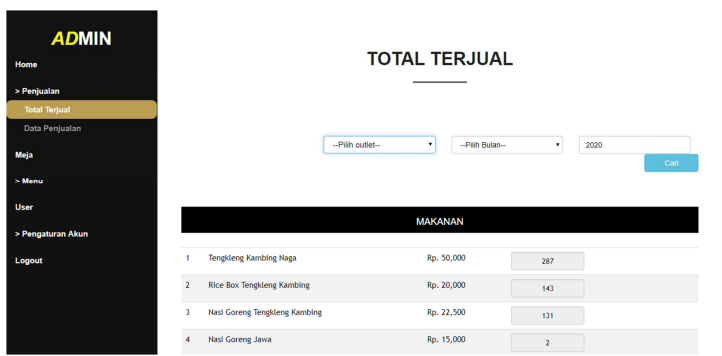

Gambar 6. Implementasi Halaman Total Terjual

Halaman total terjual berfungsi saat data yang akan ditampilkan ketika admin telah melakukan pilih outlet dan data bulan serta menginputkan tahun kapan yang akan dilakukan pentotalan makanan dan minuman yang terjual. Pada total terjual juga dapat menampilkan total terjualnya permenu pada outlet, bulan dan tahun tertentu atau secara keseluruhan. Untuk mempermudah, totalnya diurutkan dari yang paling laris hingga yang paling tidak laku.

\section{Tampilan halaman data penjualan}
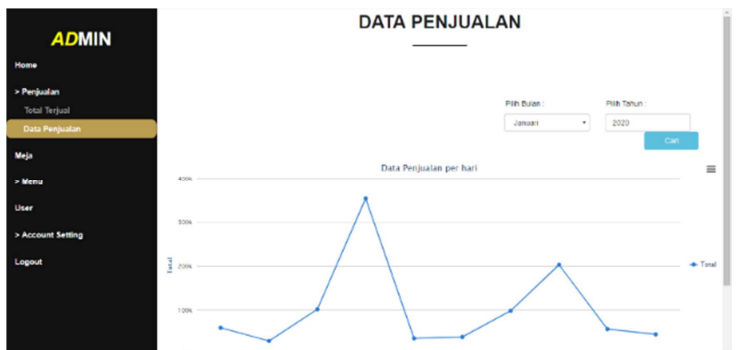

Gambar 7. Implementasi Halaman Data Penjualan

Gambar 7 menunjukkan halaman data penjualan yang berfungsi untuk melihat hasil penjualan harian semua toko berdasarkan bulan dan 
tahun tertentu. Dapat dilihat hasil penjualan bulanan untuk tahun tertentu. Data yang akan ditampilkan terlebih dahulu dipilih berdasarkan bulan dan tahun yang dimasukkan, setelah itu akan muncul grafik penjualan harian. Dan ketika semua opsi untuk bulan tersebut dipilih, grafik penjualan bulanan akan muncul.

\section{KESIMPULAN DAN SARAN}

Berikut kesimpulan yang dapat diambil dari hasil pembahasan:

1. Dengan adanya aplikasi ini diharapkan dapat membantu para pemilik usaha makanan dan minuman merekap penjualan selama satu tahun. Pemilik juga dapat melihat grafik penjualan untuk perhari atau perbulan.

2. Dengan aplikasi ini, pemilik bisnis makanan dan minuman dapat melihat total penjualan menu tertentu selama perbulan. Pemilik juga dapat melihat menu mana yang paling banyak terjual dalam satu bulan.

3. Dengan aplikasi ini pelanggan dapat dengan mudah memilih nomor meja yang akan ditempati dan pelanggan juga dapat melihat kapasitas nomor meja untuk menyesuaikan dengan jumlah orang yang ditempati.

Pada pengembangan aplikasi ini masih jauh dari sempurna karena masih banyak kekurangan. Maka pengembangan lebih lanjut dapat disarankan:

1. Ditambahkan fitur notifikasi pada halaman kasir untuk memudahkan kasir menerima pesanan. Jadi jika pelanggan sudah melakukan pembayaran saat melakukan pemesanan, maka akan muncul notifikasi di halaman checkout bahwa ada pemesanan di meja tertentu.

2. Di halaman pelanggan, ketika pelanggan menghapus menu tertentu yang dipesan sebelumnya. Pelanggan tidak dapat menghapus jumlah tertentu atau ingin menghapus semuanya. Di masa depan, sistem dapat dikembangkan sedemikian rupa sehingga pelanggan dapat menghapus sejumlah tertentu atau semuanya.

3. Diharapkan di masa mendatang, aplikasi serupa di halaman pelanggan dapat memilih jumlah yang akan dihapus dan menambahkan fungsi notifikasi di halaman kasir.

\section{DAFTAR PUSTAKA}

AYU Y. PRIMASHANTI, I., 2015. Pendekatan Perancangan Terstruktur. In: Catatan Kuliah Analisis dan perancangan Sistem. pp.1-20.

FERDIKA, M. AND KUSWARA, H., 2017. Sistem
Informasi Penjualan Berbasis Web Pada PT Era Makmur Cahaya Damai Bekasi. Information System For Educators And Professionals, 1(2), pp.175-188.

HERMAN, H.T., ROSTIANINGSIH, S. AND SETIAWAN, A., 2016. Pembuatan Aplikasi Point of Sales untuk Rumah Makan Dapur Rinjani. Infra, [online] 4, p.6. Available at: <https://media.neliti.com/media/publicati ons/108536-ID-pembuatan-aplikasipoint-of-sales-untuk.pdf $>$.

PAMUNGKAS, G. AND YULIANSYAH, H., 2017. Rancang Bangun Aplikasi Android Pos (Point of Sale) Kafe Untuk Kasir Portable Dan Bluetooth Printer. JST (Jurnal Sains dan Teknologi), 6(1), pp.199-208.

PERMANA, SILVESTER DIAN HANDY, F., 2015. Analisa Dan Perancangan Aplikasi Point Of Sale (POS) Untuk Mendukung Manajemen Hubungan Pelanggan. Jurnal Teknologi Informasi dan Ilmu Komputer, 2(1), pp.20-28.

SANI, A.S., PRADANA, F. AND RUSDIANTO, D.S., 2018. Pembangunan Sistem Informasi Point Of Sales Terintegrasi Dalam Lingkup Rumah Makan Beserta Cabangnya ( Studi Kasus: RM . Pecel Pincuk Bu Tinuk ). Jurnal Pengembangan Teknologi Informasi dan ilmu Komputer, 2(10), pp.3249-3257.

SARI, L.A., PRASETYO, Y.A. AND SANTOSA, B., 2016. Pengembangan Point Of Sales \& Inventory Manajemen Pada Aplikasi eApotik Dengan Metode Waterfall ( Studi Kasus Klinik Medika 24 ). e-Proceeding of Engineering, 3(2), pp.1-10.

SOMMERVILLE, I., 2011. Software Engineering. Clinical Engineering: A Handbook for Clinical and Biomedical Engineers.

SOUFITRI, F., 2017. Perancangan Data Flow Diagram Untuk Sistem Informasi Sekolah (Studi Kasus Pada SMA Pembangunan Laboratorium UNP). Teknoif, 2(1), pp.35-39.

SUGIHARTONO, J., SATOTO, K.I., WIDIANTO, E.D., 2015. Pembuatan Aplikasi Point of Sale Toko Cabang Perusahaan Torani Menggunakan Framework CodeIgniter. Jurnal Teknologi dan Sistem Komputer, 3(4), pp.445-455.

VERA, A., 2018. Pendekatan Perancangan Terstruktur Data Flow Diagram.

YAKUB, 2012. Pengantar Sistem Informasi. Yogyakarta: Graha Ilmu, p.163. 